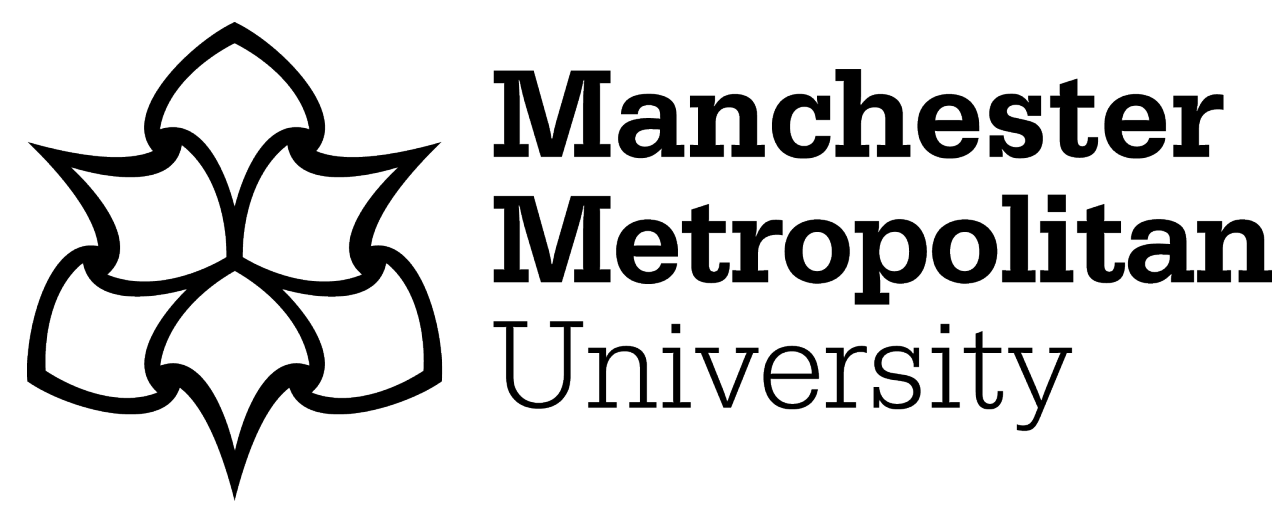

Garde, Julia Anne, van der Voort, Mascha Cécile and Niedderer, Kristina ORCID logoORCID: https://orcid.org/0000-0002-8188-6338 (2018) Design Probes for People with Dementia. In: Design Research Society Conference 2018, 25 June 2018 - 28 June 2018, University of Limerick.

Downloaded from: https://e-space.mmu.ac.uk/624376/

Version: Published Version

Publisher: Design Research Society

DOI: https://doi.org/10.21606/drs.2018.492

Usage rights: Creative Commons: Attribution-Noncommercial-Share Alike 4.0

Please cite the published version 


\title{
Design Probes for people with dementia
}

\author{
GARDE Julia Anne ${ }^{a}$; VAN DER VOORT Mascha Cécile ${ }^{a^{*}}$ and NIEDDERER Kristina ${ }^{b}$ \\ a University of Twente \\ b University of Wolverhampton \\ * Corresponding author e-mail: m.c.vandervoort@utwente.nl \\ doi: 10.21606/dma.2017.492
}

\begin{abstract}
In order to include persons with dementia in the MinD project actively, design probes were developed to provide insight into their perspectives. We applied probes due to their exploratory character and participation through self-documentation. The aim of this paper is to reflect on the design of the probes in relation to the outcomes as a source of inspiration for designers. More specifically, we investigate the openness and tangibility of the probes, and their content relating to the past, the current or the future. The five participants completed the probes to a large extent. The openness of assignments influenced their completion and the resulting value for empathizing and inspiration for designers: More defined assignments led to more sharing of personal and sensitive information than very open ones. While crafty, tangible assignments were filled in more extensively than less tangible ones, the classical writing assignments resulted more often in more introspective and reflective information from participants. Furthermore, participants filled in assignments about past memories more extensively than those relating to future goals.
\end{abstract}

Design probes; design for dementia; active participation; engagement

\section{Introduction}

The MinD project aims to use mindful design to support people with early to mid-stage dementia and their caregivers to increase their self-empowerment, confidence and wellbeing in social contexts. Dementia, often causing cognitive, behavioural and psychosocial difficulties, affects people in the social context with respect to recognizing, relating to and empathizing with other people. In addition, side effects of the situation of living with dementia might be potentially having to deal with its stigma - either imposed by others or self-perceived. These difficulties pose a challenge for engaging socially and reduce personal well-being. The MinD project employs mindful design to find ways of complementing existing care approaches to empower people with dementia in everyday social situations (Niedderer et al., 2017). The final aim is to develop solutions that enable selfempowerment and confidence of people living with dementia. 
While knowledge about abilities and disabilities of persons with dementia is valuable information in developing designs, learning about user needs and preferences is even more important (Meiland, Dröes, Sävenstedt, Bergvall-Kåreborn, \& Andersson, 2010). The majority of research published about dementia and their caregivers is quantitative in nature while in particular qualitative research has the potential to provide meaningful insights into experiences and values of people with dementia. (Carmody, Traynor, \& Marchetti, 2015). Persons with dementia themselves are often excluded from research with the result that their perspectives remain underexposed (Carmody et al., 2015). Persons with dementia and their caregivers should be actively included through qualitative research and co-design, and be considered a source of lived experience and valid knowledge (Scottish Dementia Working Group, 2014) - this is the approach the MinD project takes.

To better include people with dementia and achieve the project's aim, the MinD project includes a data collection phase to gain insights from people with dementia and their caregivers, followed by the design development phase and an evaluation phase. The data collection phase comprised focus groups, interviews, and visual probes, which were conducted in three countries (The Netherlands, Germany and Spain). The study reported here is part of the data collection phase with people with dementia, and reports on the use of design probes (also called 'Visual Diaries' or 'Do Books') in the Netherlands.

Active participation of persons with dementia in the design process requires dedicated facilitation (van Rijn, van Hoof, \& Stappers, 2010). In MinD, semi-structured interviews with people with dementia and caregivers and focus groups with caregivers have provided insights into the challenges people with dementia and their caregivers are facing regarding daily living, social engagement, decision making and the use of assistive devices (Niedderer et al, 2017). To gain additional insight into what persons with dementia consider as meaningful for their personal lives, what supports their decision making and empowerment, and what type of assistive devices they accept, we employed dedicated design probes. In this paper we report on the probe method that was developed for this aim and specifically on the results from experimenting with different types of probes as part of the data collection phase in the Netherlands during autumn 2016 and spring 2017.

The project aim and the development of the qualitative interviews and the design probes content were guided by our mindful design approach. Mindfulness values, drawing on a broad range of understandings from mindfulness and mindful design (Niedderer (2014), le, Nguyen \& Langer (2014), Langer (2010)), include awareness and acceptance (e.g. of emotions and/or situations), reflection (e.g. on emotions and/or situations), reframing situations/perspectives, choice, empowerment (resulting from choice) and wellbeing. This approach was developed to offer different perspectives and choice. The interview and design probes content was targeted to ask specifically, directly or indirectly, for aspects of mindfulness in people's lives, including indicators for empowerment, decision making and wellbeing.

\section{Design Probes}

Probes have the ability to focus on the social, aesthetic and cultural environment of participants' lives as well as their needs, feelings, values and attitudes. By allowing participants to act on open tasks or questions and determine their own focus in their answers, design probes can provide deeper insights into people's experiences, concerns and values (compared to more researcher steered methods, such as interviews and focus groups) (Mattelmäki, 2006).

Probes are items that pose a number of evocative tasks to get inspirational responses from participants that usually are fragmentary. They have a playful nature and evoke a subjective approach. Probes, as they were originally developed by Gaver, Dune \& Pacenti (1999), were not meant to gain comprehensive data on detailed research questions (Gaver, Boucher, Pennington, \& Walker, 2004). They were developed as a design method to collect inspirational data from elderly in three countries they could not speak to directly (Gaver, Dunne, \& Pacenti, 1999). 
Since Gaver's contribution, probes as a method have been applied to various areas in $\mathrm{HCl}$ and design, also in the context of dementia: Van Rijn, van Hoof, and Stappers (2010) collaborated with relatives of people with dementia in later stages (instead of the persons with dementia themselves). Brown et al., and Brankaerts and Wallace et al. applied probes directly with people with dementia (Brankaert, 2016; Brown et al., 2014; Wallace et al., 2013a). Brown et al used a camera and two workbooks to have people take pictures of their daily life, describe them in the workbooks and rate the captured situations on an emotion scale. Their aim was to elicit deeper insights in the life of persons with dementia to aid the development of assistive technologies. The probes have a strong diary character but their design in relation to the types of responses is not discussed in detail in their article (Brown et al., 2014). Wallace et al on the other hand describe their very artistic and inspirational probes in more detail, but cannot reflect on a larger number of returned probes due to only one participating couple (Wallace et al., 2013a). In another project with elderly participants (presumably without dementia), Wallace and Lindley used probes as a design tool to think with, as a "vehicles for conversation and relationship building when spending time with participants, rather than away from them" (p. 78, Wallace \& Lindley, 2014). Brankaert applied "playful probes" that included a game aspect with people with dementia to generate more interesting responses. However, in his research he does not reflect in detail on the impact of the probe designs on the responses generated (Brankaert, 2016).

The adaptability of the probes method implicates a need to describe and reflect upon the detailed use and appropriation of the method in the different contexts (Brown et al., 2014). With this paper, our aim is to explicitly report and reflect on the design of probes for persons with dementia, the process around distribution and recollection of the probes and the types of reactions and information our specific probes evoked. Particular focus is placed on the probes as a source of inspiration in relation to their openness, tangibility, and their content relating to the past, the current and the future.

\section{Probe method for active participation of people with dementia}

Our aim with the probes was to develop insight into the perspectives and life of people with dementia to enable a more empathic design approach (Koskinen, Mattelmäki, and Vaajakallio, 2014) and to identify needs, opportunities and ideas for mindful design interventions. We chose to apply probes due to their exploratory character and for more active user participation through selfdocumentation of persons with dementia. Our probes contain assignments that are ambiguous and in line with Gaver's original intentions, as well as concrete questions and even some assignments that have a strong resemblance to diary approaches in dementia research (e.g., Välimäki, Vehviläinen-Julkunen, \& Pietila, 2007).

Our point of departure is that benefits such as mutual learning (Robertson \& Simonsen, 2013) for all persons included in a design endeavour are essential to a participatory approach. With the probes, benefits for the participant were aimed at pleasure in doing the activities, enjoying personal reflection, the generation of something that they and their family can keep as a memory and, inherently, more active participation in the data collection phase of the design process.

The main advantage of probe assignments, offering an aspect of self-empowerment, is that they can be done in a self-directed manner, at the time the person with dementia wants to or feels best, in a way the person prefers to do it, as concise or elaborate as desired, by self-deciding what the focus of the answer should be, and even by deciding not to do it - which should be easier than being confronted with an interview situation which requires immediate focus and answers. As participants can do the probes in their own time and take their time to think about their contributions, we anticipated that their results would be preceded by reflection, leading to thought-through and comprehensive responses.

Moreover, design probes allow various ways of expression (e.g. writing, drawing, crafting and photographing). Qualitative research with persons with dementia poses certain challenges (Beuscher 
\& Grando, 2009) and probes potentially suit the abilities and preferences of people with dementia better than continuous concentration and eloquence by participants that is required in longer verbal communications such as interviews. To achieve these benefits, we put effort into making the probes aesthetically attractive. Also, we realized that we were taking precious time from the participants and therefore needed to be respectful by putting care and consideration into the probes. Inspired by Wallace \& Lindley (2014), we moreover hoped that this effort, once perceived by the participants, would help us to build a relationship with the participants and we were trying to create the probes in a way that they could be perceived as a gift in return for the participants' efforts.

\subsection{Probe design}

There are two types of probes, inspiration oriented probes, like the probes by Gaver et al (1999), and information oriented probes (Boehner, Vertesi, Sengers, \& Dourish, 2007). While our probes were a combination of both, in this paper we will focus on the role of probes as sources of inspiration and empathy to designers.

To serve the role as source of inspiration for design ideas, the design of the probes needed to consider comprehensiveness in relation to open-endedness as well as surprise potential for the specific target group they are developed for (Bredies, Buchmüller, \& Joost, 2008).

Working with persons with dementia, the probe design paid special attention to the type of the topics covered, the technical presentation of the assignments, and the mood they conveyed: As the abilities of persons with dementia vary a great deal, variation was introduced in the technical presentation as well as the required mode of expression for the assignments. To facilitate independent completion of the assignments, questions and instructions were formulated in short sentences and clear wording. All assignments were designed to minimize learning, feel familiar, not take away control, and reassure the user. For writing activities, the writing space was always limited to prevent participants to feel pressure about how much they were expected to write (Wallace, McCarthy, Wright, \& Olivier, 2013b). We also did not opt for traditional diary keeping, which involves much writing and might make participants more aware of their diminishing writing skills (Bartlett, 2012).

The focus of the probes was to gain more insight in the processes of change going on in participants' lives and the potential support of design herein. The probes therefore addressed the participants' awareness of change (decline and gradual loss of control) as well as their hopes and needs for preservation and enhancement. In line with the interviews, these overarching questions about change were addressed with respect to activities of daily life, leisure activities, social engagement and overall wellbeing as well as artefacts used.

The probes consisted for every participant of specially selected maps and envelopes that contained lose leafs with the assignments and additional material needed to do the assignments such as stickers, cards, mini photo albums, etc. The envelopes could either be given to the participants one by one or a few at a time or all at once. This was to be decided by the person with dementia in consultation with the caregiver.

We had writing activities varying from open questions that invited to write short episodes to simple list making. To generate visual content we had photographing assignments, for which an instant camera was used in combination with places in the probe sheets that pictures could be pasted to. The rationale was that pictures taken could be immediately put into order and place (affordance) to lower the risk that people would take pictures and later on not remember the rationale for it, as such problems have been reported from other photo projects with participants with Alzheimer's (Shell, 2014). Other activities were crafting related, such as using stickers to label or decorate paper objects. For this paper, we selected 10 of the 26 probe assignments to analyse. The selection was based on the inclusion of assignments from different topics (e.g. goals, living situation, wellbeing) and categories - open and less open assignments, assignments including more tangible items, as well as all the different activity types that were provided (see table 1 ). 
Table 1 Overview of the probe assignments (colour codes: green = open, red = not so open, blue = about the past, orange = about the future).

\begin{tabular}{|c|c|c|c|c|c|c|c|}
\hline Assignment & Focus point & $\begin{array}{l}\text { Activity } \\
\text { type }\end{array}$ & Tools & $\begin{array}{l}\text { Openness } \\
\text { with respect } \\
\text { to format }\end{array}$ & $\begin{array}{l}\text { Openness } \\
\text { with } \\
\text { respect to } \\
\text { content } \\
\end{array}$ & Tangibility & $\begin{array}{l}\text { Past, } \\
\text { present, } \\
\text { future }\end{array}$ \\
\hline $\begin{array}{l}\text { 1) What do you feel are } \\
\text { the most } \\
\text { important things that } \\
\text { you've } \\
\text { done in your life? }\end{array}$ & Goals & $\begin{array}{l}\text { writing/list } \\
\text { making }\end{array}$ & writing space & $\begin{array}{l}\text { medium } \\
\text { open, } \\
\text { suggests list } \\
\text { making }\end{array}$ & $\begin{array}{l}\text { medium - } \\
\text { things can } \\
\text { be } \\
\text { everything }\end{array}$ & No & past \\
\hline $\begin{array}{l}\text { 2) What would you like to } \\
\text { do or achieve in the } \\
\text { future? }\end{array}$ & Goals & $\begin{array}{l}\text { writing/list } \\
\text { making }\end{array}$ & writing space & $\begin{array}{l}\text { medium } \\
\text { open, } \\
\text { suggests list } \\
\text { making }\end{array}$ & $\begin{array}{l}\text { medium - } \\
\text { things can } \\
\text { be } \\
\text { everything }\end{array}$ & No & future \\
\hline $\begin{array}{l}\text { 3) Please use this object to } \\
\text { tell about what home } \\
\text { means to you personally. } \\
\text { What makes your home } \\
\text { your home and what } \\
\text { makes your } \\
\text { home beautiful? Feel free } \\
\text { to draw on/inside the } \\
\text { object, stick things onto it } \\
\text { or change it in any way } \\
\text { you see fit. (Wallace et al., } \\
2013 a \text {; Wallace et al., } \\
2013 b \text { ) }\end{array}$ & $\begin{array}{l}\text { Living } \\
\text { situation }\end{array}$ & $\begin{array}{l}\text { handicraft/ } \\
\text { writing }\end{array}$ & $\begin{array}{l}\text { Abstract 3D pop- } \\
\text { up paper house, } \\
\text { pens, stickers }\end{array}$ & very open & open & yes, 3D & today \\
\hline $\begin{array}{l}\text { 4) In which situations do } \\
\text { you feel emotionally } \\
\text { strong? } \\
\text { And in which situations } \\
\text { emotionally vulnerable? }\end{array}$ & Wellbeing & $\begin{array}{l}\text { writing/list } \\
\text { making }\end{array}$ & Writing Space & $\begin{array}{l}\text { medium } \\
\text { open, } \\
\text { suggests list } \\
\text { making }\end{array}$ & $\begin{array}{l}\text { not so open } \\
\text { - situations } \\
\text { is more } \\
\text { specific }\end{array}$ & No & today \\
\hline $\begin{array}{l}\text { 5) In which situations do } \\
\text { you feel physically strong? } \\
\text { And in which situations } \\
\text { physically weak? }\end{array}$ & Wellbeing & $\begin{array}{l}\text { writing/list } \\
\text { making }\end{array}$ & Writing Space & $\begin{array}{l}\text { medium } \\
\text { open, } \\
\text { suggests list } \\
\text { making } \\
\end{array}$ & $\begin{array}{l}\text { not so open } \\
\text { - situations } \\
\text { is more } \\
\text { specific }\end{array}$ & No & today \\
\hline $\begin{array}{l}\text { 6) If you could capture } \\
\text { anything (for instance any } \\
\text { moment, sound, song, } \\
\text { smell, view, object, } \\
\text { place...) and preserve it in } \\
\text { this jar for you to relive } \\
\text { what would you choose? } \\
\text { (Wallace et al., 2013b) }\end{array}$ & $\begin{array}{l}\text { Memory, } \\
\text { preserva- } \\
\text { tion }\end{array}$ & $\begin{array}{l}\text { handicraft, } \\
\text { write }\end{array}$ & $\begin{array}{l}\text { Paper with } \\
\text { pictures of } \\
\text { preservation jars } \\
\text { and stickers to } \\
\text { write on and } \\
\text { paste on the jars }\end{array}$ & less open & open & yes, 2D & past \\
\hline $\begin{array}{l}\text { 7) Please take } 3 \\
\text { photographs of the things } \\
\text { you tend to take with you } \\
\text { when you go out of the } \\
\text { house. Why do you like to } \\
\text { take them? }\end{array}$ & $\begin{array}{l}\text { Environme } \\
\text { nt/access }\end{array}$ & $\begin{array}{l}\text { take } \\
\text { photos, } \\
\text { write }\end{array}$ & $\begin{array}{l}\text { Camera, photo } \\
\text { album sheet, } \\
\text { with } \\
\text { assignments, } \\
\text { spots to paste } \\
\text { the polaroid } \\
\text { pictures and } \\
\text { writing space }\end{array}$ & $\begin{array}{l}\text { partly open, } \\
\text { requires } \\
\text { pictures }\end{array}$ & not so open & Yes & today \\
\hline $\begin{array}{l}\text { 8) Please tell us about } \\
\text { some things you would } \\
\text { like to be acknowledged } \\
\text { for. (Wallace et al., 2013a) }\end{array}$ & Capabilities & $\begin{array}{l}\text { Handicraft, } \\
\text { write }\end{array}$ & $\begin{array}{l}\text { paper with } \\
\text { pictures of } \\
\text { trophy cups and } \\
\text { stickers to write } \\
\text { titles on and to } \\
\text { paste on cups } \\
\end{array}$ & less open & $\begin{array}{l}\text { medium - } \\
\text { things can } \\
\text { be } \\
\text { everything }\end{array}$ & yes, 2D & today \\
\hline $\begin{array}{l}\text { 9) Which activities or daily } \\
\text { tasks do you not like to } \\
\text { delegate? Why? }\end{array}$ & ADL & $\begin{array}{l}\text { writing/list } \\
\text { making }\end{array}$ & Writing space & $\begin{array}{l}\text { medium } \\
\text { open, } \\
\text { suggests list } \\
\text { making } \\
\end{array}$ & $\begin{array}{l}\text { not so open } \\
\text { - tasks is } \\
\text { specific }\end{array}$ & No & today \\
\hline $\begin{array}{l}\text { 10) Which ones are you } \\
\text { happy for someone else to } \\
\text { do for you? Why? }\end{array}$ & $\mathrm{ADL}$ & $\begin{array}{l}\text { writing/list } \\
\text { making }\end{array}$ & Writing space & $\begin{array}{l}\text { medium } \\
\text { open, } \\
\text { suggests list } \\
\text { making } \\
\end{array}$ & $\begin{array}{l}\text { not so open } \\
\text { - tasks is } \\
\text { specific }\end{array}$ & No & today \\
\hline
\end{tabular}




\subsection{Examples of the different types of probe activities}

In this section, we describe examples of probes of the different activity types.

Probes one and two comprise writing or list making activities about achievements and future plans. They ask "What do you feel are the most important things that you have done in your life? " and "What would you like to do or achieve in the future?". These questions are provided on two sides of an A3 sheet in combination with lineated writing space and an illustration (see Figure 1).

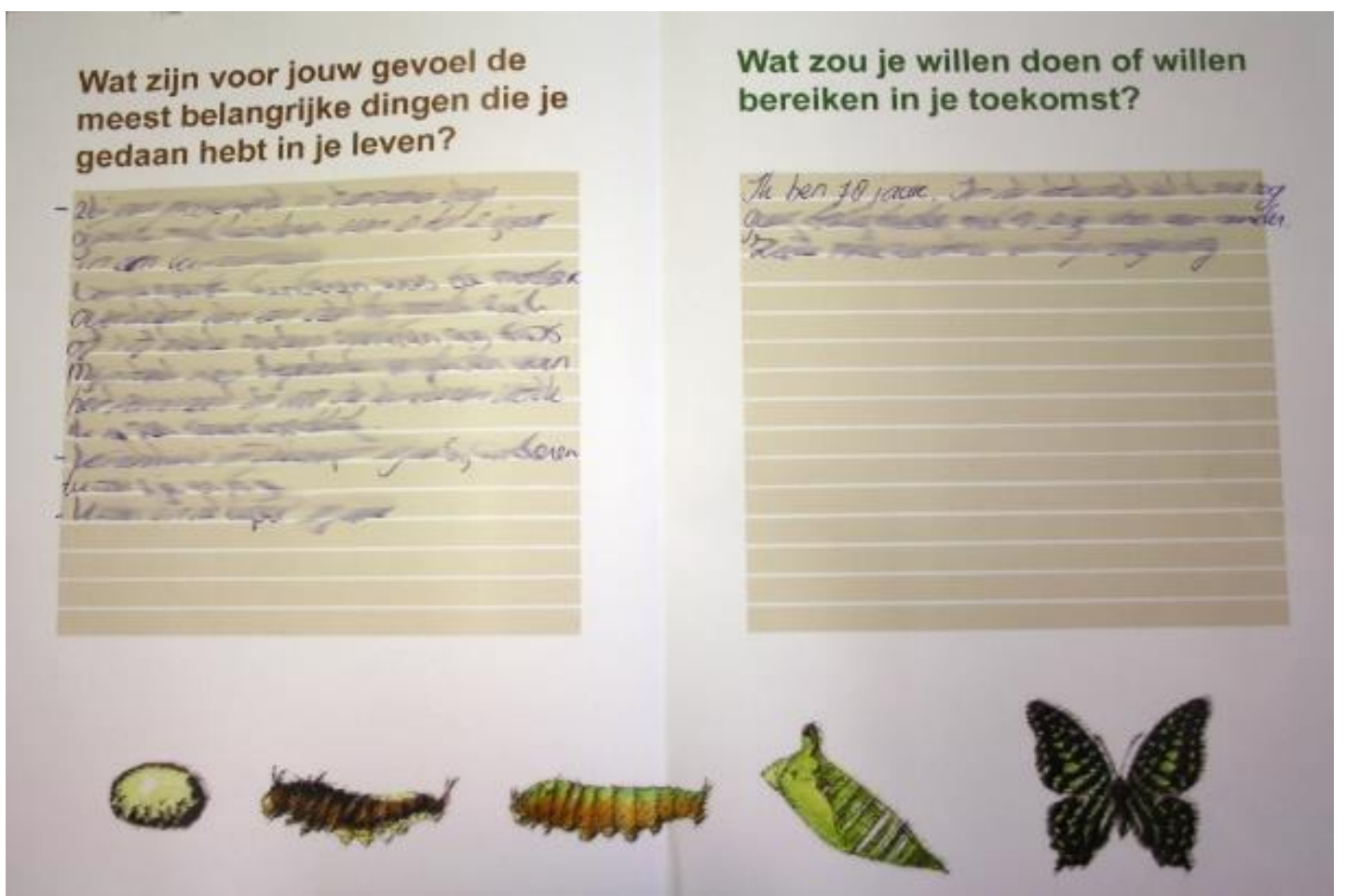

Figure 1 Assignments 1 and 2 about achievements and plans for the future, Dutch version. Handwritten entry blurred to protect privacy.

Probe three was an A3 folded sheet that that revealed a pop-up house when folded out. This assignment was based on an assignment by Wallace et al. (2013b), who used a wooden house object as probe with the instruction "Please use this object to tell about what home means to you personally. What makes your home your home and what makes your home beautiful? Feel free to draw on/inside the object, stick things onto it or change it in any way you see fit". Our house came with a set of stickers, which could be used to modify the house. It is primarily a three-dimensional handicraft activity. 


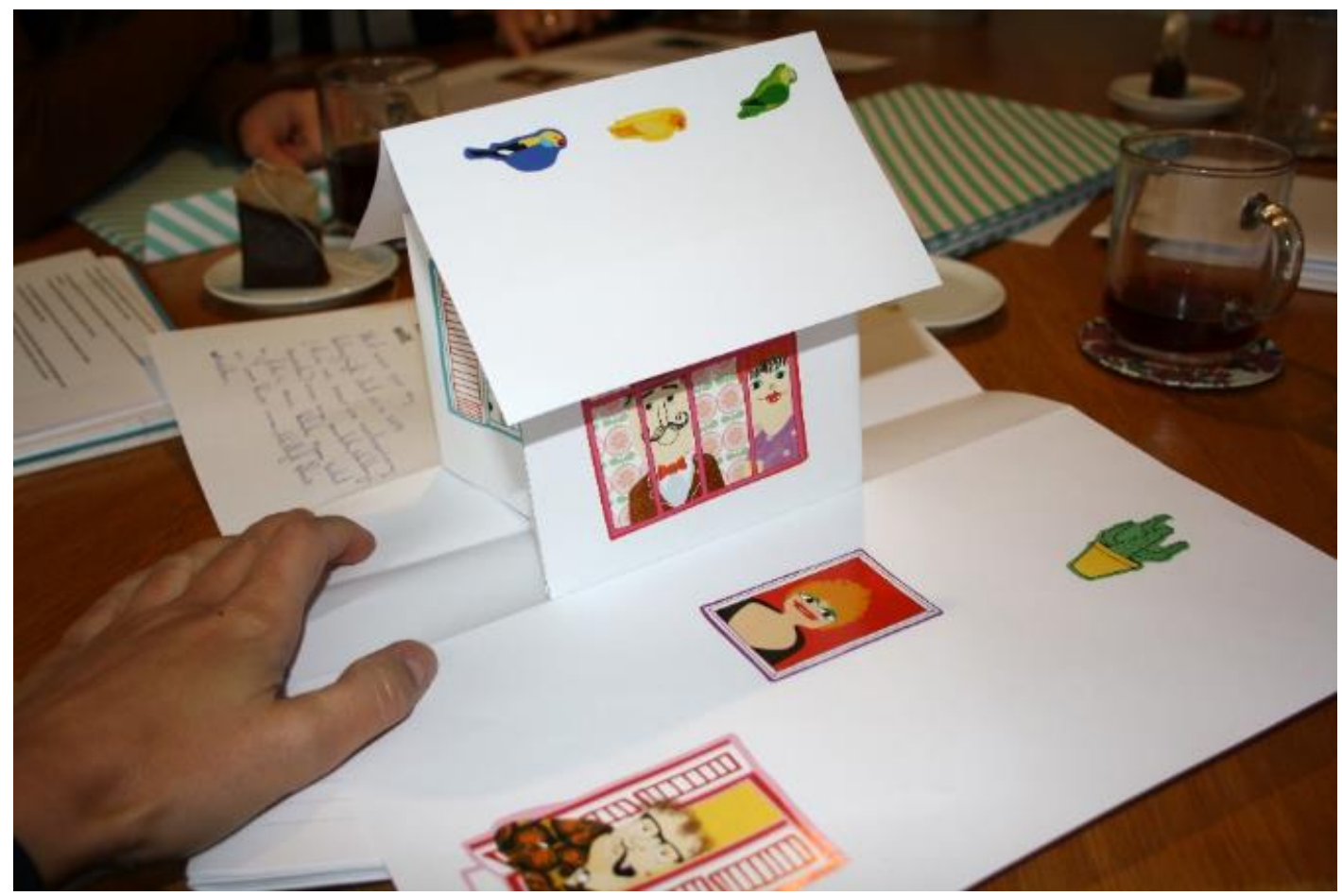

Figure 2 Assignment 3 about what "home" means, photographed during the interview with the participant. Dutch version, this one includes a handwritten description by the participant and use of many of the stickers.

Assignment six comprised pictures of preservation jars and labels that could be written and pasted onto the jars. This assignment was also based on an assignment of Wallace and McCarthy and their question "If you could capture anything (for instance any moment, sound, song, smell, view, object, place...) and preserve it in this jar for you to relive what would you choose?" (Wallace et al., 2013b). It is a handicraft assignment, similar to the pop-up house, albeit only two-dimensional.

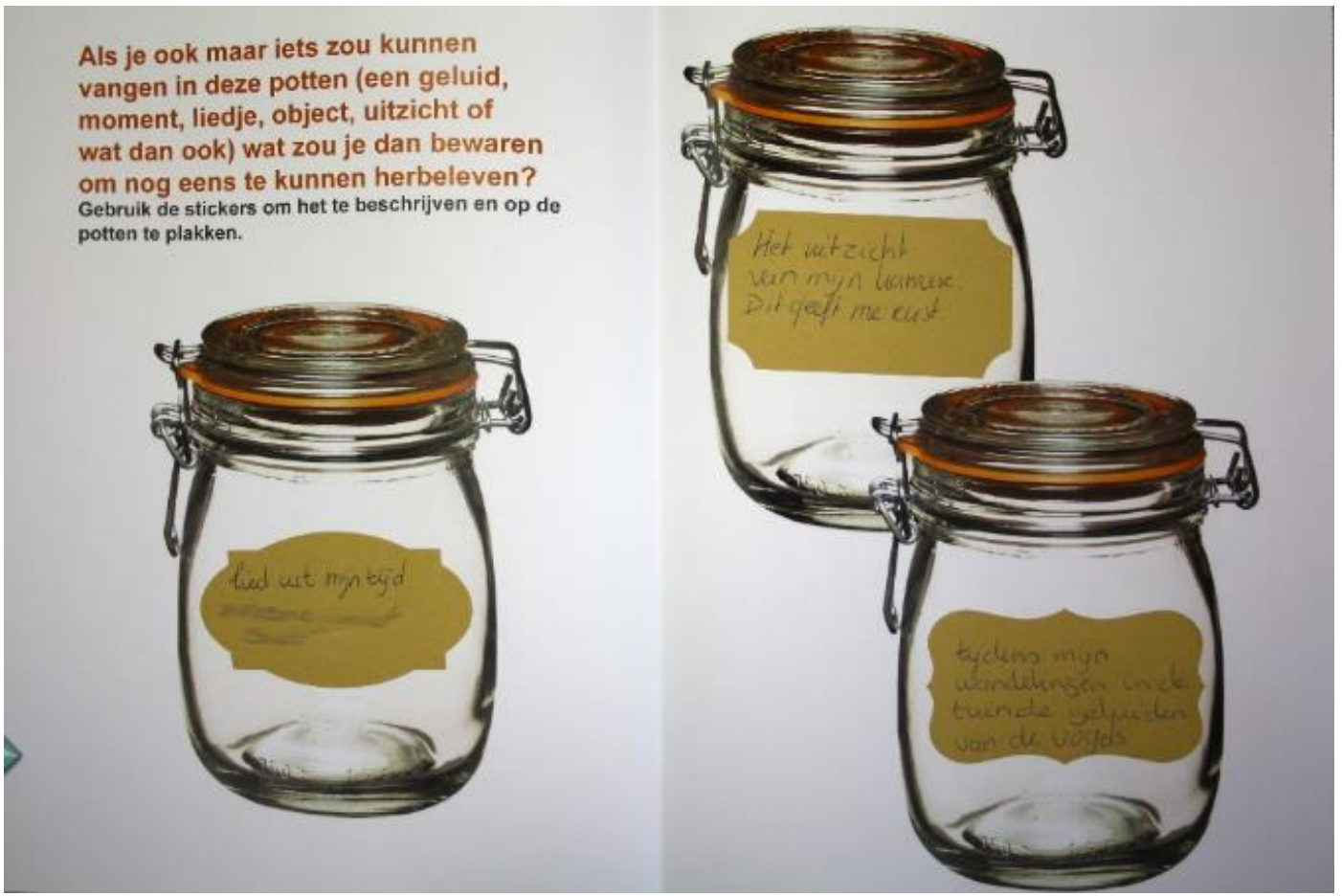

Figure 3 Assignment 6 about preservation of memories, filled in by Dutch participant. 
Assignment 7 included a photographing activity with an instant camera. The assignment was to take 3 photographs of the things participants tend to take with them when they go out of the house. This was accompanied by the request to explain in writing why they like to take them and an illustration.

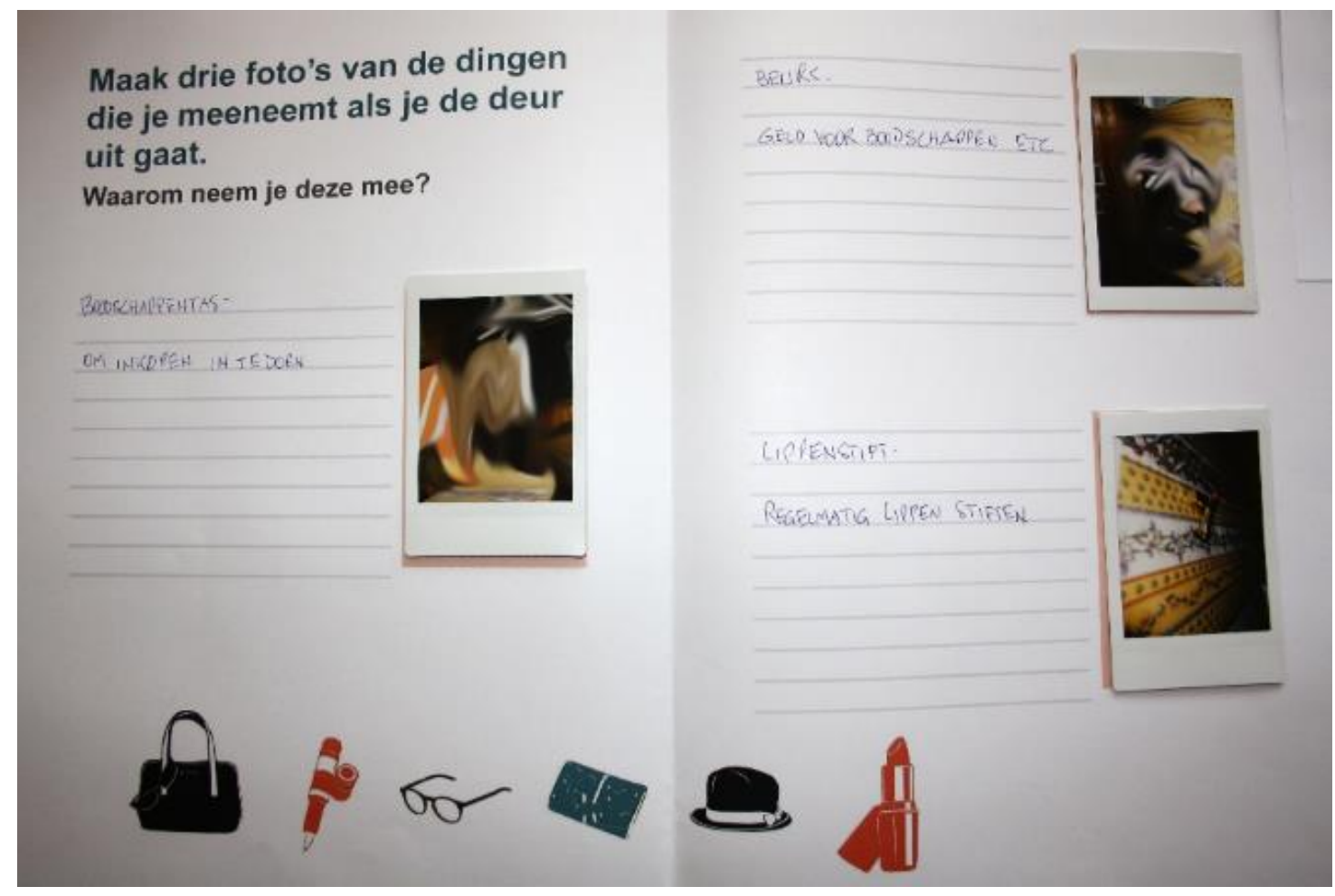

Figure 4 Assignment 7 with Photo task, filled in by Dutch participant. Pictures blurred to protect privacy.

\subsection{Process around handing out and getting back}

Five probe sets were handed out to participants in the Netherlands. The five participants were selected by case managers of a care centre in the Eastern part of the Netherlands. Applied selection criteria comprised recently diagnosed, living at home, and daily presence of care giver to support participation.

All probe sets would remain property of the participants after completion. However, with the consent of the participants, we took photos for analysis after a period of approximately four weeks. Participants were given an information and consent form saying that any information they would add to the probes map would exclusively be used for analysis and scientific presentations, and that they would stay the owners of the probes. This included "process consent", i.e. participants could decide to not to use them or not share them with the researchers in the end (Dewing, 2007).

Of the 5 handed out probe sets, 4 returned nearly completed in their entirety. One was abandoned after working on 7 out of 10 assignments analysed here. The probe sets were discussed with the participants during interviews of about an hour each. These interviews were introduced with an open request to provide some general feedback about the probes. After that, the interviewer and the participant reviewed the completed probes to discuss each assignment.

\section{Method of Analysis}

The probe sets were collected as photographs of the completed probes. These photographs were accompanied by transcripts of the interviews about the probes.

For the purposes of this paper, the probes and interviews were analysed with two foci: (1) to collect design ideas and identify areas for design intervention and (2) to find out which types of probes worked best for this purpose. In this paper, we report in detail on the second focus. This paper does 
not include details on the thematic analysis with regard to the actual content of the answers to the probes.

Our method of analysis for the second focus comprised of three steps, (1) coding of the probes, (2) coding of the accompanying interviews and (3) comparison between different probe types:

1. Each assignment in each probe set was coded to indicate if it was done, in which way it was filled in (e.g. in whole sentences or just words), how extensive it was executed, the level of personal details that were shared, and the attitude of the participant that could be elicited from the content the participant had generated (positive or negative view). Each of these aspects had several codes. In the case of personal details we coded whether participants had filled in personal information. We also coded whether participants described things in relation to interactions/relationships with others, one example being a participant who described as a future goal that she wants to keep a good relation with her son, daughter in law and the grandchildren. This was discerned from descriptions of the effects of dementia on interactions/relationships with others, e.g. someone describing being retired early due to sickness and therefore losing the contact with his colleagues. We also coded if emotions were expressed, for example when a participant described her happiness when, at some point, she was not any longer dependent on a professional caretaker for showering after the recovery from a fall accident. We coded that sensitive information was shared in case participants freely showed their own weaknesses, needs or regrets. An example is a participant who wrote that she would like to be acknowledged for what she means to her partner. We also specifically coded whether participants told anecdotes or shared motivations for their statements, deeds, choices etc.

2. The interviews were also coded but in a different way: The coding was focused on a direct evaluation of the diaries or the assignments. We coded to which assignment a statement referred or if it was a general statement about the whole probe set. Next, we discerned codes for emotional reactions, ratings of assignments as like, dislike, assignments being described as easy, difficult, inspiring, dull, or not applicable. Moreover, descriptions about how the assignments were done by the participants, were identified.

3. We compared the coding outcomes for tangible probes with intangible probe assignments, assignments that were open with respect to the content participants could fill in with less open probes as well as probe assignments that were more open with respect to the format participants could use to express themselves with assignments with less open formats. We also distinguished probes that were referring to the past (memories) with probes that were pointing to the future (plans).

\section{Outcomes}

\subsection{Overall appreciation of probes and assignments}

The interviews provided important information about how the design probes were completed and perceived: In four out of five cases the probes were completed in cooperation with the caregiver (mostly the spouse), because it was too difficult for participants to do it on their own, as was stated in the interviews. This shows that we might still have overestimated the capabilities of the participants. One person thought the work with the probes in general - unrelated to dementia - was difficult because some of the questions were hard to answer, in the sense that after a long lifetime there are many things to remember and to choose from to document. However, participants stated that the probes were filled in according to their own wishes and therefore we are confident that the story of the persons with dementia themselves was told.

Most of the assignments were filled in by making lists or noting down phrases (with the crafts oriented assignments we also asked for short, written descriptions). 
Three of the five participants stated in the interviews that, for different reasons, they did not like the probes very much. The person who had abandoned the probes after 7 assignments said the crafty assignments were not for him and were described as "childish" by him. We learned that he had had a quarrel over the probes with his spouse, because he did not want to accept any help: He had formerly worked in a job that required precise writing and had a hard time accepting the gradual loss of his skills. He said he would have preferred to just talk about these topics. A second person, although completing all assignments, did not like assignments that required confidence in his life achievements and skills. The third person told us that she felt aggrieved every time she had to work on the probes and that this had put undue pressure on her. She had filled in the assignments together with her spouse. They both discussed every item in detail, and then the spouse would document the essence of what they had concluded. During the interview, the spouse very eloquently explained everything they had filled in. In spite of negative perceptions, participants reported that they experienced benefits from completing them. They stated that the probes had been a way for them to talk about topics they would not get to talk about in daily life. Of the two remaining participants, one said that the probes were "nice", and the other was indifferent about them. They both had someone who helped them by writing for them. No one indicated the probes to be dull and two participants even found inspiration in the probes in the sense that they stimulated to discuss topics they would not normally get into in daily life.

Some assignments were indicated as not applicable to individual participants. The assignment asking people to photograph and describe items they take with them when they leave the house was named twice in this respect. However, when questioned, it did not seem to be the assignment as such but it was particular aspects of the assignment that were found to be not applicable. These included the illustrative pictures of things people might take with them, such as a lipstick (see Figure 4), which the male participants explicitly referred to as not applicable. This shows that even small details can spark discussion, if they are not designed completely gender neutral.

When looking at which probes were especially disliked, there was not one that stood out. However, looking at which probes participants liked, the pop-up house that addressed the topic home was rated positively by two participants. The probe that asked people to tell what they would like to be acknowledged for was not filled in by three participants. This is striking, given that all other probes were filled in by at least 4 out of 5 participants. For this probe, one person just filled in general values, expressed by sayings, but did not specifically link these to herself. Hence, only one participant had completed the assignment with things he/she wanted to be acknowledged for. In the interviews, participants stated that they were modest and therefore did not feel the assignment fitted them, or that they could not see much value for their current abilities and needs due to the sickness.

\subsection{Openness of probe assignments}

We were interested whether the responses to open probe assignments were more valuable for empathizing by designers (Mattelmäki, 2006) and also higher appreciated by the participants. For this aim, two types of openness of an assignment can be distinguished (see also Table 1):

1. Openness with respect to the format: an open format leaves several options to the participant to express him/herself. An example is the home assignments, where people could use the pop-up house and the page it was attached to, to draw, write, place stickers or use other ways to modify it. In comparison, the assignment were people could write things they would like to preserve on labels and place them on conservation jars more restrictive in its format, because it prescribed one way of expression.

2. Openness with respect to content describes how open the assignment is formulated. As an example, the home assignment is not only open with respect to format, but also with respect to content: it just asks to describe what home means to the participant, it does not ask for anything specific like an artefact or feeling. The same applies to the assignment with the preservation jars, hence, even though this assignment is not open with respect to the 
format it is very open with respect to the content. On the other hand, asking people to take photographs of things they like to take with them when they leave the house, is requesting very specific content.

The assignments with an open format led less often to the sharing of personal or sensitive information in our study than those which are more prescriptive with respect to format. The sharing of personal information happened nearly twice as often in assignments with less open format than in assignments with open format, the same applies to the sharing of sensitive information.

When looking at assignments with respect to openness of the content, the most personal and sensitive information were shared in assignments that were not open with respect to content. In the other categories, there was no significant difference between open and less open assignments.

\subsection{Tangibility}

An additional value of tangibility of design tools, and of using the hands in creative and learning tasks, is often claimed (e.g. (Papert, 1980)). Our probe sets consisted of several assignments with more tangible materials, such as the ones with photographing or using stickers as well as "not so tangible" assignments that used writing on a sheet of paper as only form of expression.

Overall, there was not much difference in the total percentage of assignments filled in between the tangible and not so tangible ones (16 out of 20 and 26 out of 30 assignments). However, there was a difference in how the assignments were filled in: The tangible assignments were filled in more extensively than the less tangible ones.

When looking at the sharing of personal information, there was no noteworthy difference between tangible and not tangible assignments. However, more emotions were shared in not tangible assignments. This might be due to the emphasis on writing, which might be an easier way to express differentiated emotions - easier than by drawing for example.

With respect to attitude, there were more neutral attitudes in the tangible assignments and more negative attitudes expressed in the not tangible assignments. This might be because there was less opportunity for participants to bypass topics in the assignments including writing, which could have led to upsetting feelings, causing a negative attitude.

\subsection{Recalling past, present or pointing towards the future?}

Dementia can be described as slow transformation from healthy cognitive functioning (for our participants in the past) to a loss of cognitive functions, in particular memory (for our participants in the future) (American Psychiatric Association, 1994). Besides looking at the form of the assignments, we therefore considered the different types of content, which the probes address to see whether assignments that relate to the past (memories, reminiscence) are perceived differently to those about the present or the future.

Amongst the assignments analysed, there are two that recall the past ( $A 1$ : important things done in your life; A6: capturing something for preservation), and one that points towards the future (A2: "What would you like to do or achieve in the future?"). All three assignments were completed by each of the five participants. However, the future oriented assignment was filled in less extensive than the other two, the to-do list was in all cases shorter, than the "done" list (3.4 VS 1.6 items on average). This could be interpreted on the one hand as a reluctance to make plans for the future because of the prospect of the illness, and was characterised by statements such as: "not many expectations for the future anymore" or because people feel they have done all the important things in their life and are content, e.g. "I am 78 years old". There were no significant differences in the sharing of personal information and the attitude was mostly neutral. 


\section{Discussion}

Even though some participants disliked parts of the probes, the interviews revealed that they completed them because of the perceived relevance and importance of the research. One could argue therefore that participants felt empowered by the probes because they felt they were helping with the research. Furthermore, indirectly, we learned a lot about living with dementia from the people who did not fully complete the diaries, just because there was more discussion and more trying to explain and reflection by them in the interviews.

Our participants were people in the early stages of dementia. Nevertheless, most participants had dementia related difficulties working on the probes by themselves, especially the writing posed problems. This points towards using more tangible assignments using other forms of expression than writing, which however led to less sharing of personal details. Moreover, tangible probes without writing require people to remember what they meant to say at the time they made the probes, which also can be an issue.

For several participants, the probes sparked deep conversations and discussions between spouses, which was not anticipated by us. Future probes could consider this in the design to focus more on both partners and their potentially differing perspectives (e.g. the perception of safety when a person with dementia is out and about on his/her own) and the relationship between the two.

The openness of assignments clearly influenced their completion and the resulting value for empathizing and inspiration for designers. More defined assignments led to more sharing of personal details, which provides important insights and therefore is most valuable for designers. This seems to indicate that people reveal this personal part of themselves only if explicitly asked to do so. In contrast, if assignments are open, people chose not to share personal and sensitive information. This finding is contrary to other researchers' work, who stated that the less instructive the probe tasks were, the more reflective and suitable the answers were for deducing inspirations for concrete design solutions (Bredies et al., 2008). The difference here might be in what is considered valuable information for design or what kind of topics the prescriptive probes address. We sought to learn about people's deeper needs, dreams and motivations, which is inspiring information that however does not directly lead to design ideas.

Assignments with open format or content were however more often filled in than closed assignments. This appears to indicate that more specific questions, which ask for specific information and a specific way to provide this information, are more polarizing and led more often to people rejecting them. The open format also seems to lead to more extensive answers, while for assignments with open content we cannot claim the same. Both open format and content also led more often to a positive attitude. Assignments with more prescriptive content were generally met with a more negative attitude, possibly because people could not circumvent topics that they perceived as difficult.

The more tangible assignments were filled in more extensively than "less tangible" ones and the attitude was more often neutral while the attitude with the less tangible assignments was more often negative. However, in order to generate introspective and reflective information (e.g. emotions) from participants, traditional writing might work better than the crafty assignments. Describing an emotion by drawing or photographing is experienced as more difficult. Therefore, it might be useful to request a written description of any tangible material made in the probes. This, however, undermines the intention to offer various ways of expression to participants with different preferences. Another option is to complement tangible probes with interviews, which however requires remembering what the probes intended to express at the time made. As we analysed only a limited number of assignments, more research about the connections between openness, tangibility and the value of the probes for inspiration and empathizing is needed.

From a first analysis of the content of the probes, it appears that our participants prefer to address memories and achievements from the past over making plans for the future. Provided it is 
considered important for mental health to have plans for the future, this is an interesting area for further investigation in the content analysis of the diaries in the MinD project as well as to explore the potential that probe design can have in this. Detailed analysis of the content of the probes will be presented elsewhere. See table 2 for an overview of the most remarkable results.

Table 2 Overview of how probes were filled in in relation to their openness, tangibility and relation to the past or the future.

\begin{tabular}{|c|c|c|c|}
\hline & $\begin{array}{l}\text { Sharing of personal details } \\
\text { (incl. emotions) }\end{array}$ & $\begin{array}{l}\text { Filled in } \\
\text { extensively }\end{array}$ & $\begin{array}{l}\text { Attitude of } \\
\text { content filled in } \\
: 0=\text { negative } \\
: \dot{\theta}=\text { positive }\end{array}$ \\
\hline tangible & & $\mathrm{V}$ & \\
\hline "not so tangible", mostly writing & V & & : \\
\hline open content & & & ;) \\
\hline prescriptive content & $\mathrm{V}$ & & 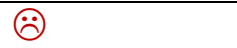 \\
\hline open format & & $\mathrm{V}$ & (;) \\
\hline prescriptive format & $\mathrm{V}$ & & \\
\hline about past & & $\mathrm{V}$ & \\
\hline about future & & & \\
\hline
\end{tabular}

\section{Conclusion}

Most probes were completed in cooperation with the caregiver, because it was too difficult for participants to do this on their own. Making the probes and assignment formulations even simpler, however, may not be a solution, as the problem was not in understanding the assignments, but in developing adequate responses. Importantly, the interviews revealed that the process of completing the probes jointly led to conversations regarding topics they would not normally get into in daily life, which was perceived as enriching and inspirational. Cooperative work on probes to stimulate this effect could be a valuable goal for the future. However, to guarantee the perspective of the individual with dementia is taken into account, separate interviews about the probes with the person with dementia and the partner might be necessary.

Interestingly, we found that more open assignments do not equal more inspirational reactions by the participants. The most open assignments generally provided less personal information and less sharing of emotions and needs. To gain such kind of information, the assignments with prescriptive content and writing as technique worked best, most likely as there was less opportunity for participants to bypass upsetting topics. However, while classic writing assignments led to more sharing of emotions and sensitive information, more tangible assignments led to more extensive replies and are generally appreciated by the participants. This means that in order to receive inspirational, personal and sensitive data, prescriptive assignments and the writing technique need to be used, paired with more open, tangible assignments for more engagement. Further research is needed to understand how we can encourage people with dementia to consider their future, and what they can do (rather than what they can't), since the importance of doing things, including new things and being of help to others has been a strong thread throughout responses to interviews conducted as part of the MinD project ${ }^{1}$.

In summary, we can say about designing the probes that:

- Prescriptive format and content, employing writing is most useful for eliciting personal detail

${ }^{1}$ publication forthcoming 
- Tangible, open format assignments, and assignments about the past are most successful in eliciting more detailed responses

- Open content assignments and assignments about the future are most challenging in eliciting responses, and future work needs to be done to address this

While most assignments were completed, some of the output needed explanation by the participants to understand the meaning of and reasons for what they had made or written. Therefore, we recommend to always pair probes with a follow-up interview to get insight into underlying needs and values, in particular in those cases where more in-depth inspiration is intended to be gained from probes.

With regard to providing a pleasurable experience to participants, even though the probe assignments were not greatly liked by all our participants, the assignments were completed in most cases. The reason for not liking them was that participants felt challenged in completing them. Moreover the reflective character of some assignments was at times perceived as confronting. The main reason for completing them was that actively participating in the research gave the participants a sense of contribution, which is in line with the findings of the MinD project1 that it is important for people with dementia to still be able to help users and be useful. The dichotomy between challenge for and contribution by participants will be an issue for future research.

Finally, the study indicated that the more active participation in the research was beneficial in terms of both the ability to contribute and help as well as in facilitating enriching interaction between people with dementia and caregivers.

Acknowledgements: First and foremost we would like to thank our participants, who have given us a large portion of their time and so much valuable information. We also gratefully acknowledge the support of Zorggroep Sint Maarten to spread the probes and during the interviews as well as the contribution of Valerie van der Linden (KU Leuven) to conducting the interviews. We would also like to thank all the colleagues from the MinD project who have given us feedback along the way or have helped to put the diaries physically together -particularly the colleagues who participated in the secondments in Germany, the Netherlands and Barcelona in September/October 2016.

The MinD project has received funding from the European Union's Horizon 2020 research and innovation programme under the Marie Skłodowska-Curie grant agreement No 691001. This document reflects only the author's view and the Research Executive Agency is not responsible for any use that may be made of the information it contains.

\section{References}

American Psychiatric Association (1994). Diagnostic and statistical manual of mental disorders. DSM-IV-TR. 4th edition. Washington DC.

Bartlett, R. (2012). Modifying the Diary Interview Method to Research the Lives of People With Dementia. Qualitative Health Research, 22(12), 1717-1726.

Beuscher, L., \& Grando, V.T. (2009). Challenges in Conducting Qualitative Research with Persons with Dementia. Research in Gerontological Nursing, 2(1), 6-11.

Boehner, K., Vertesi, J., Sengers, P., \& Dourish, P. (2007). How HCl Interprets the Probes. In Proceedings of the SIGCHI Conference on Human Factors in Computing Systems (CHI '07) , 1077-1086. New York, NY, USA: ACM. DOI: https://doi.org/10.1145/1240624.1240789

Brankaert, R. (2016). Design for Dementia. PhD thesis. Eindhoven: Eindhoven University of Technology.

Bredies, K., Buchmüller, S., \& Joost, G. (2008). The gender perspective in cultural probes. In Proceedings of the Tenth Anniversary Conference on Participatory Design 2008, 92-101. Bloomington, IN, USA: ACM.

Brown, M., Tsai, A., Baurley, S., Koppe, T., Lawson, G., Martin, J. L., Coughlan, T., Elliott, M., Green, S., Arunachalam, U. (2014). Using Cultural Probes to Inform the Design of Assistive Technologies. Proceedings of $\mathrm{HCl}$ International 2014.

Carmody, J., Traynor, V., \& Marchetti, E. (2015). Barriers to Qualitative Dementia Research: The Elephant in the Room. Qualitative Health Research, 25(7), 1013-1019. 
Dewing, J. (2007). Participatory research: A method for process consent for people who have dementia. . Dementia: Interantional Journal of Social Research and Practice, 6(1), 11-25.

Gaver, B., Dunne, T., \& Pacenti, E. (1999). Cultural Probes. Interactions, January/February, 21-28.

Gaver, W. W., Boucher, A., Pennington, S., \& Walker, B. (2004). Cultural Probes and the Value of Uncertainty. Interactions, 11(5), 53-56.

le, A., Ngnoumen, C. T., \& Langer, E. J. (2014). Origins and theory. In A. le, C. T. Ngnoumen, and E. J. Langer (Eds.). The Wiley Blackwell Handbook of Mindfulness (pp. 1-5). Chichester, UK: John Wiley \& Sons, Ltd.

Koskinen, I. Mattelmäki, T, Vaajakallio, K (2014) What Happened to Empathic Design? Design Issues: Volume 30 (1), 67-77.

Langer, E.J. (2010). Counterclockwise. London, UK: Hodder \& Stoughton Ltd.

Mattelmäki, T. (2006). Design Probes. Helsinki: Publication Series of the University of Art and Design Helsinki..

Meiland, F., Dröes, R.-M., Sävenstedt, S., Bergvall-Kåreborn, B., \& Andersson, A.-L. (2010). Identifying User Needs and the Participative Design Process. In M. D. Mulvenna \& C. D. Nugent (Eds.). Supporting People with Dementia Using Pervasive Health Technologies, Advanced Information and Knowledge Processing, 79100. London: Springer-Verlag.

Niedderer, K. (2014). Mediating Mindful Social Interactions through Design. In le, A., Ngnoumen, C.T. and Langer, E. (Eds). The Wiley Blackwell Handbook of Mindfulness, Vol 1, pp345-366. Chichester: Wiley.

Niedderer, K., Tournier, I., Colesten-Shields, D., Craven, M., Gosling, J., Garde, J.A., Bosse, M., Salter, B., Griffioen, I. (2017) Designing with and for People with Dementia: Developing a Mindful Interdisciplinary CoDesign Methodology. In: Proceedings of the IASDR international Conference 2017, Cincinnati, USA. DOI:10.7945/C2G67F Proceedings

Papert, S. (1980). Mindstorms: children, computers, and powerful ideas. New York: Basic Books.

Robertson, T., \& Simonsen, J. (2013). Participatory Design; An introduction. In T. Robertson \& J. Simonsen (Eds.). Routledge International Handbook of Participatory Design, 1-17. New York, USA: Routledge.

Scottish Dementia Working Group. (2014). Core principles for involving people with dementia in research: Innovative practice. Dementia, 13(5), 680-685. doi:10.1177/1471301214533255

Shell, L. (2014). Photo-Elicitation with Autodriving in Research with Individuals with Mild to Moderate Alzheimer's Disease: Advantages and Challenges. Int. Journal of Qualitative Methods, 13, 170-184.

Välimäki, T., Vehviläinen-Julkunen, K., \& Pietila, A.-M. (2007). Diaries as research data in a study on family caregivers of people with Alzheimer's disease: methodological issues. Journal of Advanced Nursing, 59(1), 68-76.

van Rijn, H., van Hoof, J., \& Stappers, P. J. (2010). Designing Leisure Products for People With Dementia: Developing "the Chitchatters" Game. American Journal of Alzheimer's Disease \& Other Dementias, 25(1), 74-89.

Wallace, J., \& Lindley, S. (2014). The Flexible Realities of Using Design Probes: Reflections from a Care Home Studying and Designing Technology for Domestic Life, 75-92. San Francisco, USA: Morgan Kaufmann.

Wallace, J., McCarthy, J., Wright, P. C., \& Olivier, P. (2013b). Making Design Probes Work. In W. E. Mackay, S. Brewster, \& S. Bodker (Eds.), CHI '13: Proceedings of the SIGCHI Conference on Human Factors in Computing Systems (pp. 3441-3450). New York: Association for Computing Machinery. DOI: $10.1145 / 2470654.2466473$

Wallace, J., Wright, P. C., McCarthy, J., Green, D. P., Thomas, J. and Olivier. P. (2013a). A design-led inquiry into personhood in dementia (video). In CHI '13 Extended Abstracts on Human Factors in Computing Systems (CHI EA '13). ACM, New York, NY, USA, 2883-2884. DOI: http://dx.doi.org/10.1145/2468356.2479560.

About the Authors:

Julia Garde is assistant professor at the University of Twente. Her research focuses on design games and participatory design in health care.

Kristina Niedderer is Professor of Design and Craft at the University of Wolverhampton. Her research focuses on the role of design to engender mindful interaction and behaviour change. She leads the European project 'Designing for People with Dementia', MSCA grant No 691001.

Mascha van der Voort is Professor of Human Centred Design at the University of Twente. Her research aims at facilitating all stakeholders to be actively involved in the development of new products \& services and decision making processes. 